ARTigo OrIGINAL

Original Article

\title{
Avaliação da proteína amilóide A sérica na atividade clínica da artrite reumatóide $e^{(*)}$
}

\author{
Evaluation of the serum amyloid A protein \\ in the rheumatoid arthritis clinical activity
}

\author{
Carlos Roberto Machado Gayer ${ }^{(1)}$, Geraldo da Rocha Castelar Pinheiro ${ }^{(2)}$, \\ Carlos Augusto Ferreira de Andrade ${ }^{(3)}$, Sérgio Miranda Freire ${ }^{(4)}$ e Marsen Garcia Pinto Coelho ${ }^{(5)}$
}

\section{RESUMO}

A artrite reumatóide (AR) é uma doença auto-imune, crônica, caracterizada pelo comprometimento inflamatório das articulações sinoviais periféricas. A proteína amilóide A sérica (SAA) é uma das principais proteínas de fase aguda (PFA), porém seu uso na rotina do laboratório clínico ainda é pouco difundido. Objetivo: O objetivo deste trabalho foi analisar a utilidade da SAA na avaliação da atividade clínica da AR. Métodos: Foram estudados 113 pacientes com AR, diagnosticados segundo os critérios do Colégio Americano de Reumatologia. Para a caracterização da atividade de doença, foi utilizado o Índice de Atividade de Doença (IAD), proposto pela Liga Européia Contra o Reumatismo. Resultados: A SAA apresentou correlação positiva, estatisticamente significativa, com a proteína C-Reativa (PCR), tanto como a $\alpha$-1-glicoproteína ácida (AGP), quanto com o IAD. Nossos resultados demonstraram que a SAA apresentou, particularmente, uma maior sensibilidade na determinação da atividade inflamatória da AR, em comparação às outras PFA. Apresentou, também, uma boa capacidade de discriminar os grupos de atividade moderada e alta do IAD. Como o IAD não mede unicamente o componente inflamatório da AR, a dosagem de uma PFA é de grande utilidade para a caracterização da atividade dessa enfermidade. Conclusões: Os resultados deste estudo sugerem que a SAA pode ser de grande valor na determinação da atividade inflamatória da AR.

Palavras-chave: Artrite reumatóide, proteínas de fase aguda, proteína amilóide A sérica, índice de atividade de doença.

\begin{abstract}
Rheumatoid arthritis (RA) is a systemic autoimmune disease, with chronic inflammation of synovial peripheral joints as the most prominent feature. The serum amyloid A (SAA) is one of the major acute phase proteins (APP), however its use in the clinical laboratory routine is uncommon. Objective: The aim of this work was to analyze the usefulness of SAA in the evaluation of RA clinical activity. Methods: We studied 113 patients diagnosed with RA according to the criteria of the American College of Rheumatology. The disease activity was evaluated by the Disease Activity Score (DAS) according to the European League Against Rheumatism. Results: SAA presented positive correlation, statistically significant, with $C$-reactive protein (CRP), as well as $\alpha$-1-acid glycoprotein (AGP) and DAS. The results demonstrated that $S A A$ presented a higher sensibility in relation to other APP in the determination of the inflammatory activity on RA patients. SAA also shows a good capability to discriminate the groups of moderate and high activity of DAS. As DAS doesn't measure only the inflammatory behavior of RA, the determination of APP is of great usefulness for the activity characterization of this illness. Conclusions: Our data suggest that $S A A$ can be of great value in the determination of the $R A$ inflammatory activity.
\end{abstract}

Keywords: Rheumatoid arthritis, acute phase proteins, serum amyloid A protein, Disease Activity Score (DAS).

\footnotetext{
* Trabalho realizado no Departamento de Bioquímica do Instituto de Biologia Roberto Alcântara Gomes, em conjunto com a Disciplina de Reumatologia da Faculdade de Ciências Médicas, ambos do Centro Biomédico da Universidade do Estado do Rio de Janeiro - UERJ. Apoio financeiro: FAPERJ. Recebido em 26/07/02. Aprovado, após revisão, em 04/02/03.

1. Biólogo do Departamento de Bioquímica do IBRAG-UERJ. Mestre em Biologia.

2. Professor adjunto da Disciplina de Reumatologia da FCM-UERJ - Doutor em Medicina.

3. Médico reumatologista do HUPE-UERJ - Mestre em Engenharia Biomédica. Doutorando em Saúde Pública (ENSP/FIOCRUZ).

4. Professor adjunto da Disciplina de Informática Médica da FCM-UERJ - Doutor em Engenharia Biomédica.

5. Professor adjunto do Departamento de Bioquímica do IBRAG-UERJ - Doutor em Bioquímica.
}

Endereço para correspondência: Carlos Roberto Machado Gayer. Rua Elisa Fonseca, 66 ap. 102, CEP 21340-070, Rio de Janeiro, RJ, e-mail: gayer@uerj.br 


\section{INTRODUÇÃO}

A artrite reumatóide (AR) é uma doença inflamatória crônica, caracterizada pelo comprometimento inflamatório das articulações sinoviais periféricas, acometendo aproximadamente $1 \%$ da população mundial ${ }^{(1)}$.

Por ser uma doença de natureza predominantemente imunoinflamatória, a monitoração clínico-laboratorial do processo inflamatório tem um grande valor na avaliação da mesma. Por causa das limitações da avaliação clínica na determinação da intensidade da atividade inflamatória, uma importância cada vez maior tem sido dada à avaliação laboratorial. Com esse objetivo, as determinações da proteína C-Reativa (PCR) e da velocidade de hemossedimentação (VHS) têm sido os testes mais utilizados ${ }^{(2)}$.

Nos últimos anos, a proteína Amilóide A sérica (SAA), uma proteína de fase aguda (PFA), com grande sensibilidade e amplitude de resposta, vem se destacando na literatura como um marcador precoce de atividade inflamatória ${ }^{(3)}$. Seu uso na rotina do laboratório clínico, porém, ainda é pouco difundido.

O nome da SAA é derivado de sua semelhança bioquímica e imunoquímica com a amilóide A encontrada na amiloidose secundária. A amiloidose secundária é uma séria complicação de doenças inflamatórias crônicas, caracterizada pela deposição de fibras protéicas insolúveis em vários órgãos ${ }^{(4)}$. O principal componente dessas fibras amilóides é derivado da clivagem proteolítica da SAA, por remoção do fragmento C-terminal ${ }^{(5)}$. A SAA pertence à família das apolipoproteínas (Apo) e são sintetizadas por hepatócitos em resposta a citocinas, especialmente interleucina-1 (IL-1) e fator de necrose tumoral alfa (TNF- $\alpha$ ), produzidas por monócitos e macrófagos ${ }^{(6)}$.

Cliffon et al. ${ }^{(7)}$ sugerem que a SAA possui propriedades aterogênicas. Logo que a SAA é liberada na circulação, ela rapidamente se associa à terceira fração de lipoproteínas de alta densidade (HDL3), substituindo as apolipoproteínas A1 (Apo A1) e Apo A2 e pode constituir de $17 \%$ a $87 \%$ das Apos presentes na HDL na fase aguda. As alterações mais comuns das frações lipídicas na fase aguda relacionadas com a SAA são diminuição de colesterol HDL e Apo A1 e aumento de triglicerídeos e da fração VLDL (lipoproteína de densidade muita baixa).

A concentração de SAA pode aumentar de $3 \mathrm{mg} / \mathrm{L}$ a 1.000 $\mathrm{mg} / \mathrm{L}$ em 24 a 48 horas após um estímulo inflamatório agudo e manter-se em níveis altos na inflamação crônica. A SAA e a PCR são as proteínas de fase aguda de maior amplitude na resposta inflamatória ${ }^{(8)}$. Como o metabolismo da
SAA é diferente do da PCR, isso sugere uma utilidade prática na avaliação da resposta de fase aguda ${ }^{(9)}$.

Algumas das doenças que têm sido monitoradas pela SAA são: $A R$, artrite crônica juvenil, artrite reativa, doença de Still, síndrome de Behçet, doença de Crohn e neoplasias associadas com a SAA derivada da amilóide, tais como doença de Hodgkin e carcinoma de $\operatorname{rim}^{(10)}$. Outro estudo recente demonstra que a SAA é um bom marcador para a espondilite anquilosante ${ }^{(11)}$.

O objetivo principal deste trabalho foi analisar a utilidade da dosagem da SAA na avaliação da atividade clínica da artrite reumatóide, tendo como objetivo secundário comparar os níveis da SAA em relação a outras proteínas de fase aguda.

\section{PACIENTES E MÉTODOS}

Foram avaliados 113 pacientes com AR, segundo os critérios de classificação do Colégio Americano de Reumatologia $^{(12)}$, acompanhados no ambulatório da reumatologia do Hospital Universitário Pedro Ernesto - UERJ. A doença foi considerada ativa quando preenchia, pelo menos, 3 dos 4 critérios a seguir: 9 ou mais articulações dolorosas, 6 ou mais articulações edemaciadas, rigidez matinal com pelo menos 45 minutos de duração e velocidade de hemossedimentação (VHS) de Westergren maior ou igual a $28 \mathrm{~mm} / \mathrm{h}^{(13)}$. Foram excluídos os pacientes que apresentavam outras condições inflamatórias não provenientes da AR.

A capacidade funcional foi avaliada pelo questionário de avaliação do estado de saúde, conforme o Stanford Health Assessment Questionnaire (HAQ), adaptado por Ferraz et al. ${ }^{(14)}$.

Para a caracterização da atividade de doença, foi utilizado o Índice de Atividade de Doença (IAD), proposto pela Liga Européia contra o Reumatismo (EULAR - European League Against Rheumatism) ${ }^{(15)}$. Este índice foi obtido a partir do uso de diferentes variáveis clínicas (número de articulações doloridas, número de articulações edemaciadas e avaliação global de saúde pelo médico) e uma variável laboratorial (VHS).

A fórmula para o cálculo do IAD é a seguinte:

$\mathrm{IAD}=0,54(\sqrt{\mathrm{IAR}})+0,065(\mathrm{NAE})+0,33(\ln \mathrm{VHS})+$ 0,0072 (AGS)

Em que: IAD - Índice de atividade de doença.

IAR - Índice articular de Ritchie ${ }^{(16)}$.

NAE - Número de articulações edemaciadas avaliadas pelo reumatologista, sendo verificadas 53 articulações.

In VHS - Logaritmo neperiano da velocidade de hemossedimentação (VHS), avaliada pelo método de Westergren. 
AGS - Avaliação Global de Saúde, em uma escala visual de 0 a 100.

O EULAR categoriza o IAD em três grupos de atividade: baixa $(\leq 2,4)$, moderada $(>2,4$ a $\leq 3,7)$ e alta $(>3,7)$ atividade. Os valores do IAD foram calculados pelo programa Epi Info 6.04 (CDC - Center for Disease Control and Prevention, Atlanta, USA).

Com o objetivo de uma maior padronização dos resultados, apenas um dos co-autores (CAFA) realizou o exame articular. Para que não houvesse sugestionamento em relação às variáveis clínicas, este co-autor não conhecia dados de prontuário, exames laboratoriais ou aspectos relacionados com o tratamento.

Todos os pacientes foram submetidos a exame radiológico das mãos em incidência ântero-posterior. A presença ou não de erosão óssea foi avaliada por médico radiologista. Este não conhecia as características clínicas e/ou laboratoriais dos pacientes.

A VHS foi realizada pelo método de Westergren ${ }^{(17)}$. Utilizamos a técnica de ELISA (Enzyme-Linked Immuno Sorbent Assay), adaptado de Sipe e colaboradores ${ }^{(18)}$, com kits adquiridos da Hemagen Diagnostic Inc. (USA), na determinação das concentrações séricas da SAA.

Os resultados do teste de SAA para os soros de 16 voluntários sadios apresentaram média de $6,7 \pm 3,9 \mu \mathrm{g} / \mathrm{mL}$. Assim, o valor de corte fornecido pelo fabricante do kit (SAA $>10 \mu \mathrm{g} / \mathrm{mL}$ ), para definir a presença de inflamação, foi mantido.

Para a dosagem da $\alpha-1$-glicoproteína ácida (AGP), PCR e do Fator Reumatóide (FR), foi utilizado o método automatizado de nefelometria em equipamento Beckman "Array 360" (Beckmam Instruments, Brea, USA). Foram considerados como valores de referência: SAA $>10 \mu \mathrm{g} / \mathrm{mL}$, PCR $>0,8 \mathrm{mg} / \mathrm{mL}$, AGP $>125 \mathrm{mg} / \mathrm{mL}$ e FR $\geq 40 \mathrm{UI} / \mathrm{mL}$. Não foi levada em consideração neste estudo a terapêutica em uso pelo paciente.

Todos os pacientes que participaram do estudo assinaram um termo de consentimento informado, previamente aprovado pelo Comitê de Ética em Pesquisa desta Instituição.

\section{ANÁLISE ESTATÍSTICA}

Os testes para verificação da distribuição Gaussiana (normal) das variáveis foram realizados pelo método de Kolmogorov-Smirnov (K-S). Foi realizada análise de variância (ANOVA) para verificar se haviam diferenças entre os grupos do IAD. A seguir, aplicou-se o procedimento de Bonferroni como teste de comparações múltiplas para análise dos grupos em pares. Para os testes não-paramétricos, utilizou-se o método de Kruskal-Wallis. O nível de significância foi de 5\% para rejeitar a hipótese nula. Para o cálculo das correlações entre variáveis, foram utilizados os coeficientes de correlação de Pearson e Spearman para as variáveis que seguiam distribuição normal ou não, respectivamente ${ }^{(19)}$.

\section{RESULTADOS}

As características clínicas e demográficas dos 113 pacientes estão resumidas na Tabela 1. Observa-se a predominância de pacientes do sexo feminino com idade média de 50 anos. Foram baixos o nível de escolaridade e de renda familiar. O tempo médio de doença foi de $11,7 \pm 10,4$ anos, variando de 1 a 52 anos. O fator reumatóide estava presente em $67 \%$ dos casos e o comprometimento erosivo das articulações, em 94\%.

A análise descritiva das variáveis SAA, PCR, AGP e VHS estratificadas pelos grupos de atividade baixa, moderada e alta, de acordo com o IAD, mostra com maiores detalhes como cada variável se apresenta em relação aos grupos de atividade. Esses resultados podem ser visualizados na Figura 1.

Os resultados dos testes de correlação pelo método de Spearman $(\mathrm{rS})$, entre as variáveis IAD, SAA, PCR, AGP e VHS; e o resultado pelo método de Pearson ( $r$ ), entre as variáveis IAD, HAQ e AGP, mostram que houve correlação, estatisticamente significativa, entre todas as variáveis. O resultados das correlações entre as variáveis IAD, SAA, PCR, AGP, VHS e HAQ estão resumidos na Tabela 2.

TABELA 1

CARACTERÍSTICAS CLÍNICAS E DEMOGRÁFICAS DOS 113 PACIENTES COM AR

\begin{tabular}{|c|c|}
\hline Idade (anos) & $50,8 \pm 13,7(19-78)^{1}$ \\
\hline $\mathrm{N}^{0}$ pacientes do sexo feminino (\%) & $101(89,4 \%)^{2}$ \\
\hline Escolaridade (anos de estudo) & $5,9 \pm 3,5(0-18)^{1}$ \\
\hline Renda Familiar (salários mínimos) & $4,3 \pm 3,5(1-20)^{1}$ \\
\hline Tempo de doença (anos) & $11,7 \pm 10,4(1-52)^{1}$ \\
\hline № de pacientes com erosão articular (\%) & $106(93,8 \%)^{2}$ \\
\hline Índice de Atividade de Doença (IAD) & $4,71 \pm 1,37(1,61-8,66)^{1}$ \\
\hline $\begin{array}{l}\text { HAQ (questionário de avaliação de estado } \\
\text { de saúde) }\end{array}$ & $1,21 \pm 0,65(0-2,8)^{1}$ \\
\hline $\mathrm{N}^{\circ}$ de pacientes com FR positivo (\%) & $76(67,3 \%)^{2}$ \\
\hline
\end{tabular}


Todos os 113 pacientes se encontravam com doença ativa $(\mathrm{IAD} \geq 1,61)$. Comparou-se o número de pacientes com valores acima e abaixo do VR (valor de referência) das PFA. A SAA apresentou sensibilidade de $76 \%$, com diferença estatisticamente significativa em relação às outras determinações (teste $\left.\chi^{2} ; \mathrm{p}<0,001\right)$. A Tabela 3 apresenta esses resultados.

Comparando a sensibilidade das PFA entre os grupos de atividade de doença, novamente a SAA apresentou maior sensibilidade. Quanto ao tempo de doença, tanto nos pacientes com 2 anos ou menos, quanto naqueles com mais de 2 anos, a SAA apresentou maior sensibilidade (resultado não mostrado).
Dezenove pacientes (16,8\% do total de 113) apresentaram, simultaneamente, concentrações das PFA (SAA, PCR e AGP) na faixa de referência ou abaixo delas e 38 pacientes $(33,6 \%)$ apresentaram valores simultaneamente superiores aos valores de referência.

\section{DISCUSSÃO}

A dosagem das PFA é uma forma mais objetiva de quantificar a atividade de doença. Destacamos o estudo da SAA, motivados pela semelhança cinética com a $\mathrm{PCR}^{(20)}$ e por ainda ser objeto de estudos recentes nesta área.
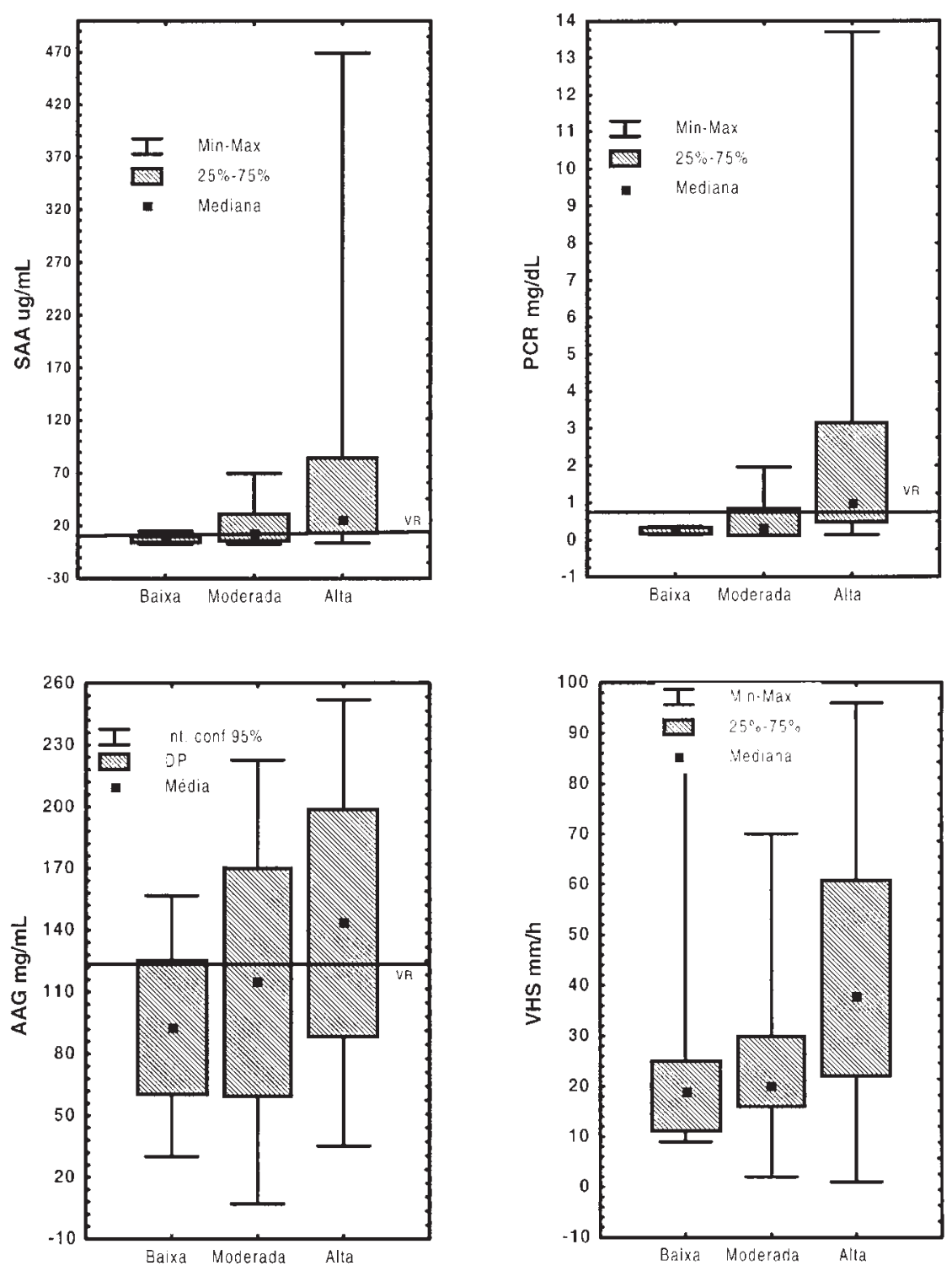

Figura 1 - Gráficos da análise descritiva das proteínas de fase aguda estratificadas pelos grupos de atividade do índice de atividade de doença (IAD). Grupos: baixa $(\mathrm{N}=6)$, moderada $(\mathrm{N}=23)$ e alta $(\mathrm{N}=$ 84); proteína amilóide $A(S A A)$; proteína C-reativa (PCR); $\alpha$-1-glicoproteína ácida (AGP) e a velocidade de hemossedimentação (VHS); valor de referência do método (VR). 
O parâmetro clínico utilizado no presente estudo é o IAD, proposto pela EULAR, sendo um método validado e cada vez mais utilizado na prática clínica, principalmente na Europa, para avaliar a atividade de doença da AR. Entretanto, este método muitas vezes reflete alterações não relacionadas unicamente à atividade inflamatória. Assim, o IAD também continua sujeito a avaliações subjetivas, pois um dos parâmetros de maior peso para seu cálculo é o Índice Articular de Ritchie, que é baseado apenas na avaliação e quantificação do grau de dor articular, a qual é subjetiva. Dessa forma, deve-se ter cuidado ao analisar articulações edemaciadas e/ou doloridas, principalmente na doença de longa duração, já que se pode não estar avaliando inflamação, mas sim seqüela.

Outro ponto relevante é que a avaliação global de saúde, um dos parâmetros do IAD, além de ser subjetiva, depende de outras variáveis que não só a inflamação (incapacidade funcional, efeitos colaterais de drogas, depressão, entre outras). Outro aspecto importante consiste na dependência da VHS para o cálculo do IAD. Este é um método indireto da avaliação da resposta inflamatória que é influenciado por outros fatores além do grau de inflamação articular. São exemplos dessa interferência o transporte do sangue, idade, sexo e uso de medicamentos ${ }^{(21)}$.

Os pacientes estudados apresentaram características demográficas comuns a esta doença, ou seja, predominantemente do sexo feminino e idade média de $50 \operatorname{anos}^{(22)}$. O longo tempo de doença, associado ao baixo nível socioeconômico e à escolaridade, explica, provavelmente, a alta incidência de doença erosiva $(93,8 \%)$ e diminuição da capacidade funcional (HAQ médio de 1,21).

\section{TABELA 2}

CORRELAČ̃ÉS ENTRE AS VARIÁVEIS

IAD, SAA, PCR, AGP, VHS E HAQ

\begin{tabular}{llllll}
\hline & IAD & SAA & PCR & AGP & VHS \\
\hline IAD & & $0,493^{\mathrm{a}}$ & 0,547 & $0,480^{\mathrm{b}}$ & 0,302 \\
SAA & $0,493^{\mathrm{a}}$ & & 0,737 & 0,614 & 0,491 \\
PCR & $0,547^{\mathrm{a}}$ & $0,737^{\mathrm{a}}$ & & 0,597 & 0,435 \\
AGP & $0,460^{\mathrm{b}}$ & $0,614^{\mathrm{a}}$ & 0,597 & & 0,538 \\
VHS & $0,302^{\mathrm{a}}$ & $0,491^{\mathrm{a}}$ & 0,435 & 0,538 & \\
HAQ & $0,684^{\mathrm{b}}$ & $0,392^{\mathrm{a}}$ & 0,432 & 0,492 & $0,232^{*}$ \\
\hline
\end{tabular}

$a=$ correlações de Spearman $(p<0,01) ;{ }^{*}=(p<0,02) ; b=$ correlações de Pearson $(p<0,01)$. Índice de atividade de doença (IAD), proteína amilóide $A$ sérica $(S A A)$, proteína C-reativa (PCR), $\alpha 1$-glicoproteína ácida (AGP), velocidade de hemossedimentação (VHS) e questionário de avaliação de saúde (HAQ).
Como descrito na literatura, observou-se uma alta correlação da SAA com a PCR $(r=0,737)$, mostrando uma similaridade na forma de resposta a estímulos produzidos durante o curso da AR. Este resultado corrobora dados encontrados por Gabay e Kushner ${ }^{(8)}$.

Todas as PFA apresentam correlação positiva com o IAD. As correlações do IAD com a SAA, PCR e AGP foram iguais a $0,49,0,55$, e 0,46 , respectivamente. Estes valores indicam um relacionamento apenas de moderado a baixo entre o IAD e aquelas proteínas. Deve ser enfatizado que, para a correlação entre o IAD e as variáveis SAA, PCR e VHS, foi calculado o coeficiente de correlação de Spearman, o qual considera não os valores originais das respectivas variáveis, mas sim a posição de cada um dos valores de cada variável, quando os mesmos são dispostos em ordem crescente. Desse modo, a interpretação dos coeficientes obtidos não é mesma que se obtém a partir do coeficiente de correlação de Pearson em termos de coeficiente de determinação $\left(\mathrm{r}^{2}\right)$.

As variáveis SAA e PCR, quando estratificadas em grupos de atividade (baixa, moderada e alta), mostraram-se capazes de discriminar, apenas, os grupos de moderada e alta atividade.

TABELA 3

Distribuição DO NÚMERO DE PACIENTES COM AR EM ATIVIDADE CLÍNICA, TOTALIZADOS E ESTRATIFICADOS EM GRUPOS DE ATIVIDADE, QUE APRESENTARAM VALORES DE CONCENTRAÇÃO DAS PROTEÍNAS DE FASE AGUDA SUPERIORES AOS VALORES DE REFERÊNCIA (VR)

\begin{tabular}{|c|c|c|c|c|}
\hline VR & $\begin{array}{c}\text { Total de } \\
\text { pacientes } \\
(\mathrm{N}=113)\end{array}$ & $\begin{array}{c}\text { Baixa } \\
\text { atividade } \\
(\mathrm{N}=6)\end{array}$ & $\begin{array}{l}\text { Moderada } \\
\text { atividade } \\
(\mathrm{N}=23)\end{array}$ & $\begin{array}{c}\text { Alta } \\
\text { atividade } \\
(\mathrm{N}=84)\end{array}$ \\
\hline $\mathrm{SAA}>10$ & 86 & 1 & 14 & 71 \\
\hline \multirow[t]{2}{*}{$\mu \mathrm{g} / \mathrm{mL}$} & $(76,1 \%)^{*}$ & $(16,6 \%)^{*}$ & $(60,9 \%)^{*}$ & $(84,5 \%)^{*}$ \\
\hline & $p<0,001^{a}$ & $n s^{a}$ & $\mathrm{p}=0,037^{\mathrm{a}}$ & $p<0,001^{a}$ \\
\hline \multirow{3}{*}{$\begin{array}{l}\mathrm{PCR}>0,8 \\
\mathrm{mg} / \mathrm{mL}\end{array}$} & 56 & 0 & 6 & 50 \\
\hline & $(49,6 \%)^{*}$ & & $(26,1 \%)^{*}$ & $(59,5 \%)^{*}$ \\
\hline & $n s^{b}$ & $n s^{b}$ & $n s^{b}$ & $p=0,009^{b}$ \\
\hline \multirow{3}{*}{$\begin{array}{l}\mathrm{AGP}>125 \\
\mathrm{mg} / \mathrm{mL}\end{array}$} & 41 & 1 & 8 & 32 \\
\hline & $(38,1 \%)^{*}$ & $(16,6 \%)^{*}$ & $(34,8 \%)^{*}$ & $(38,1 \%)^{*}$ \\
\hline & $P<0,001^{c}$ & $\mathrm{~ns}^{\mathrm{c}}$ & $\mathrm{ns}^{\mathrm{c}}$ & $p<0,001^{c}$ \\
\hline
\end{tabular}

Proteína amilóide $\mathrm{A}(\mathrm{SAA})$; proteína C-reativa (PCR) e $\alpha$-1-glicoproteína ácida (AGP). ${ }^{*}$ ) número absoluto de pacientes de acordo com o grupo (\% em relação ao número de pacientes do grupo estratificado). $\left({ }^{\mathrm{a}}\right)$ valor de $\mathrm{p}$ em SAA $\times$ PCR pelo método $\chi^{2} ;{ }^{(b)}$ valor de $p$ em PCR $\times$ AAG pelo método $\chi^{2}$; $\left({ }^{c}\right)$ valor de $p$ em SAA $\times$ AAG pelo método $\chi^{2}$; (ns) não significativo. 
A AGP, apesar de apresentar uma correlação positiva com o IAD, não discriminou os grupos de atividade do IAD. Além disso, a maioria das concentrações obtidas estava dentro de sua faixa de referência. Dessa forma, nos pacientes deste estudo, a AGP não foi útil para caracterizar a atividade de doença.

A VHS não foi útil para caracterizar os grupos de atividade do IAD e apresentou uma baixa correlação com o mesmo $\left(r_{\mathrm{s}}=0,302\right)$.

Foi analisada a sensibilidade das PFA para revelar a atividade inflamatória da AR, utilizando os valores de referência das mesmas. Observou-se que a SAA foi a PFA que apresentou a maior sensibilidade (76\%) na determinação da atividade inflamatória. Essa sensibilidade foi observada tanto nos pacientes de início recente (menor e igual a 2 anos) quanto de doença tardia (dados não apresentados).

$\mathrm{O}$ pequeno número de pacientes $(\mathrm{N}=14) \mathrm{com} \mathrm{AR}$, de início recente, não permitiu avaliar a possível interferência do tempo de doença no IAD.

Como todos os pacientes precisavam estar em atividade de doença para serem incluídos no estudo, não foi surpresa encontrar um valor mínimo do IAD de 1,61. Observou-se que $16,8 \%$ dos pacientes apresentaram, simultaneamente, concentrações das PFA dosadas na faixa ou abaixo do valor de referência (VR), mostrando que o IAD não estava refletindo, necessariamente, a atividade inflamatória.

Em mais da metade dos casos (57\%), não houve concordância nos valores das PFA, possivelmente porque possuem catabolismo diferente e pelo fato da síntese das PFA ser regulada por diferentes citocinas ${ }^{(23)}$. Este achado evidencia a limitação da determinação de uma única PFA no estudo da resposta inflamatória.

As discrepâncias observadas entre O IAD e as PFA podem ser entendidas por diferentes cenários. Em alguns casos, uma única grande articulação inflamada (exemplos:

\section{REFERÊNCIAS}

1. Harris ED Jr: Rheumatoid Arthitis, Pathophysiology and Implications for Therapy. New Eng J Med 332(18):1277-89, 1990.

2. Richardson C, Emery P: Laboratory markers of disease activity. J Rheumatol 44(suppl): 23-30, 1996.

3. Uhlar MA, Whitehead AS: Serum amyloid A, the major vertebrate acute-phase reactant. Eur J Biochem 265:501-23, 1999

4. Husby G, Marhaug G, Dowton B, Sletten K, Sipe JD: Serum Amyloid A (SAA): biochemistry, genetics and pathogenesis of AA amyloidosis. Int J Exp Clin Invest 1:119-37, 1994. ombro e joelho) pode gerar grande estímulo na produção de PFA, mas o IAD tende a ser de valor baixo. Por outro lado, um grande número de pequenas articulações (exemplos: mãos e pés) em atividade tende a gerar um alto valor do IAD, mas o estímulo para a produção das PFA pode não ser intenso.

Outro fator importante é que os medicamentos chamados de segunda linha ou drogas anti-reumáticas modificadoras de doença (DMARD), como, por exemplo, sulfasalazina, penicilamina e methotrexate, podem diminuir a produção de $\mathrm{PFA}^{(24,25)}$, principalmente quando combinados com os glicocorticóides ${ }^{(26)}$.

Nossos resultados ratificam o conceito de que o IAD não mede apenas a atividade inflamatória da doença. Dessa forma, a dosagem de pelo menos mais uma PFA é de grande importância na avaliação da atividade da AR.

Dentre as PFA estudadas, verificou-se que a SAA apresentou uma maior sensibilidade na investigação da inflamação. Além disso, outro fator que estimula a sua utilização é a observação de que a produção da SAA, diferentemente da VHS e PCR, não é influenciada por terapia com sulfasalazina, sais de ouro ou penicilamina ${ }^{(27)}$.

Os resultados deste estudo sugerem que a SAA é uma PFA com grande potencial na determinação da atividade inflamatória da AR. Novos estudos, preferencialmente, prospectivos, fazem-se necessários para confirmar a utilidade da dosagem da SAA na monitoração da atividade inflamatória em pacientes com AR.

\section{AGRADECIMENTOS}

À Dra. Gabriela M.B. Silva e à Dra. Renata C. Figueiredo, pela valiosa colaboração no acompanhamento clínico dos pacientes.

5. Pepys MB, Baltz ML: Acute Phase Proteins with special reference to C-Reactive protein and related proteins (pentaxis) and Serum Amyloid A Protein. Adv Immunol 34:141-211, 1983.

6. Jensen LE, Whitehead AS: Regulation of serum amyloid A protein expression during the acute phase response. Biochem J 334:489503, 1998 .

7. Clifton PM, Mackinnom AM, Barter PJ: Effects of serum amyloid A protein (SAA) on composition, size, and density of high density lipoprotein in subjects with myocardial infarction. J Lipid Res 26:1389-98, 1985.

8. Gabay C, Kushner I: Acute Phase Protein and Other Systemic Responses to Inflammation. New Engl J Med 11:448-54, 1999. 
9. Steel DM, Whitehead AS: The major acute phase reactants: Creactive protein, serum amyloid $\mathrm{P}$ component and serum amyloid A protein. Immunol Today 15:81-8, 1994.

10. De Beer FC: Serum amyloid A protein concentration in inflammatory disease and its relationship to incidence of reactive systemic amyloidosis. Lancet 2:231-3, 1982.

11. Lange U, Boss B, Teichmann J, Klor HU, Neeck G: Serum amyloid $A$ an indicator of inflammation in ankylosing spondylitis. Rheumatol Int 19:119-22, 2000.

12. Arnett FC, Edworthy SM, Bloch DA, et al: The American Rheumatism Association 1987 revised criteria for the classification of rheumatoid arthritis. Arthritis Rheum 31:315-24, 1988

13. Strand V, Tugwell P, Bombardier C, et al: Function and healthrelated quality of life: results from a randomized controlled trial of leflunomide versus methotrexate or placebo in patients with active rheumatoid arthritis. Arthritis Rheum 42(9):1870-78, 1999.

14. Ferraz MB, Oliveira LM, Araujo PM, Atra E, Tugwell P: Crosscultural reliability of the physical ability dimension of health assessment questionarie. Rheumatol 17(6):813-17, 1990.

15. Van Gestel AM, Prevoo MLL, Van't Hof MA, Van Rijswijk MH, Van de Putte LBA, Van Riel PLCM: Development and validation of the European League against Rheumatism response criteria for rheumatoid arthritis. Arthritis Rheum 39:34-40, 1996.

16. Richie DM, Boyle JA, McInnes JM, et al: Clinical studies with an articular index for the assessment of joint tenderness in patients with rheumatoid arthritis. Q J Med 37: 393-406, 1968.

17. ICSH recommendations for measurement of erythrocyte sedimentation rate. International Council for Standardization in Haematology (Expert Panel on Blood Rheology), J Clin Pathol 46(3):198-203, 1993
18. Sipe JD, Gonnerman WA, Loose LD, Knapschaefer G, Xie WJ Franzblau C: Direct binding enzyme-linked immunosorbent assay (ELISA) for serum amyloid A (SAA). J Immunol Methods 125:12535, 1989.

19. Dawson-Sauders B, Trapp RG: Basic \& Clinical Biostatistics, $2^{\text {nd }}$ ed, NY, Ed Appleton \& Lange, 1994.

20. Giltin JD, Colten HR: Molecular biology of the acute phase plasma proteins. In: Pick E, Lany M, Eds. Lymphokines. Academic Press, San Diego Calif, 1987.

21. Cecin HA, Almeida AC: Hemossedimentação: depois de 80 anos, ainda útil. Rev Bras Reumatol 39:59-61, 1999.

22. Engel A: Rheumatoid Arthritis in US adults 1960-2. In: Bennet P, Wood PHN. Population studies of rheumatic disease. Amestardam: Expercta Med 83-89, 1968.

23. Tillet, WS, Francis, TJ: Serological reactions in pneumonia with a non-protein somatic fraction of pneumococcus. J Exp Med 52:561, 1930.

24. Situnayake RD, McConkey B: Clinical and laboratory effects of prolonged therapy with sulfasalazine, gold or penicillamine: the effects of disease duration on treatment response. J Rheumatol 17:126873, 1990.

25. McConkey B, Crockson RA, Crockson AP, et al: The effects of some anti-inflammatory drug on the acute-phase proteins in rheumatoid arthritis. Q J Med 42:785-91, 1973.

26. Taylor HG, Fowler PD, David MJ, Dawes PT: Intra-articular steroids: confounder of clinical trials. Clin Rheumatol 10: 3842,1991 .

27. Grindulis KA, Scott DL, Robinson MW, Bacon PA McConkey B: Serum amyloid A protein during the treatment of rheumatoid arthritis with second-line drugs. Br J Rheumatol 24:158-63, 1985. 